\title{
INTERMINADOS, CRIADORES E SONHADORES: O PROBLEMA DA ESTÉTICA EM PAULO FREIRE
}

\author{
POR ARISTÓTELES BERINO
}

\section{RESUMO}

Apesar de não ter despertado a devida atenção entre os principais intérpretes da sua obra, o problema da estética em Paulo Freire constitui um núcleo importante do seu pensamento. Entre os seus escritos, nas suas conversações e práticas pedagógicas, o tema da estética sempre esteve presente, desde o início da sua trajetória intelectual e de educador até seus últimos trabalhos publicados. Neste artigo, procuro mostrar algumas dessas referências e proponho um caminho analítico que passa pelo conceito de criação para entendermos como especialmente o tema da estética está relacionado a sua concepção de educação. Diante do avanço do neoliberalismo, o conceito de sonho encontra na sua obra uma articulação política que também associo ao significado que atribuía à criação como possibilidade emancipatória e promotora de outros sentidos à existência.

\section{ABSTRACT}

Despite not having called the attention of the main interpreters of his work, Paulo Freire's problem of aesthetics constitutes an important nucleus of his thought. Among his writings, in his conversations and pedagogical practices, the theme of aesthetics has always been present, since the beginning of his intellectual and educator career until his last published works. In this article I try to show some of these references and propose an analytical path that goes through the concept of creation in order to understand how the theme of aesthetics is especially related to his conception of education. Faced with the advance of neoliberalism, the concept of dream finds in his work a political articulation that I also associate to the meaning that he attributed to creation as an emancipatory possibility and promoter of other meanings to existence.

\section{KEYWORDS}

Paulo Freire; Creation; Dream.

\section{PALAVRAS-CHAVE}

Paulo Freire; Criação; Sonhos.

\footnotetext{
' Universidade Federal Rural do Rio de Janeiro (UFRRJ) Curso de Pedagogia do campus Nova lguaçu da UFRRJ e Programa de Pós-Graduação em Educação Contextos Contemporâneos e Demandas populares (PPGEduc/UFRRJ)
} 
Suas atividades noturnas, seus bailes, sua música, o uso do corpo, seus gestos, sua maneira de andar, de vestir, suas crenças, sua ironia, seu humor, sua forma de "desperta-se" de situações difíceis,sua semântica, sua sintaxe...

Paulo Freire (1982, p. 57))

O pretendido com este artigo é prosseguir em uma discussão que tenho me detido mais recentemente a respeito do problema da estética no pensamento de Paulo Freire. Em outro momento (BERINO, 2017), procurei sinalizar para a possibilidade mesmo de vermos Paulo Freire aproximativamente como um esteta. No caso, alguém que valorava a beleza e se utilizava também dos sentidos da arte para pensar a própria educação. Então, buscando progredir com a minha pesquisa sobre a estética no pensamento de Paulo Freire, espero caminhar um pouco mais aqui, destacando particularmente as noções de criação e sonho na sua obra, como atividades constitutivas da experiência educativa tal como ele a concebia, uma atividade geradora de mundos genuinamente humanos - vale dizer, sempre social e culturalmente referidos.

Não foram poucas as vezes que Paulo Freire referiu-se explicitamente ao campo da estética entre os seus escritos e nas suas conversações como parte da sua concepção de educação. Curiosamente, trata-se de uma observação que não costuma ser destacada pelos intérpretes da sua obra. Paulo Freire é frequentemente lembrado pelo sentido político que atribuiu à educação e pela possibilidade emancipatória que via aí. O que gostaria de lembrar neste artigo é que política e estética são elementos indissociáveis da sua concepção de educação. Agora, no primeiro quarto do século XXI, quando discutimos o legado de Paulo Freire e a sua atualidade, mais do que nunca, é preciso situar adequadamente o lugar da estética na sua obra.

No seu último livro publicado ainda em vida, Pedagogia da autonomia, de 1997, Paulo Freire $(2015$, p. 34) incluiu no primeiro capítulo, dedicado à prática 
docente, em destaque, a observação de que "ensinar exige estética e ética". Trata-se de um rápido subcapítulo em que vai qualificar o caráter formador da prática educativa em oposição à concepção que reconhece nela apenas um treinamento técnico. Caráter formador em que ética e estética caminham juntas, ele diz. Há uma ordem de grandeza na formação da qual a estética faz parte. A palavra estética é utilizada por ele em outras passagens do texto (p. 26, 46 e 58, por exemplo). No entanto, não encontramos, apesar das várias referências, uma discussão mais elaborada sobre o tema. Apesar de provocados para a questão, não ficamos sabendo o que é exatamente a estética na educação para Paulo Freire neste livro. Em outra dessas passagens, a estética é associada à "boniteza" (p. 34). Mais adiante, referese ao "gosto estético" do aluno como uma dimensão da autonomia do ser do educando (p. 48). São algumas pistas, mas um tanto dispersas, sobre o que representam para a sua concepção de estética na educação.

Na medida em que vamos percorrendo outras das suas obras, a presença do tema da estética vai se amplificando. Já na sua primeira publicação, Atualidade e educação brasileira, de 1959, Paulo Freire (2002, p. 102) emprega a expressão "currículo plástico" para referir-se à necessidade de romper com o rígido currículo que caracterizava a estrutura das escolas de formação de professores. Criticava um aspecto "verboso" presente no ensino que precisava dar lugar a um aumento de trabalhos de ordem prática. Um currículo que se identificasse com a nossa atualidade, concluía. Para indicar uma concepção curricular que acreditava renovada, instituinte, Paulo Freire usa um adjetivo - "plástico" - frequentemente utilizado no meio artístico (ex.: artista plástico, obra plástica). Não se trata de uma escolha fortuita, casual, vamos ver.

Se olharmos para a trajetória de Paulo Freire como educador, vamos encontrar algumas referências profissionais que são significativas também para a minha discussão aqui. Nos anos 1950, foi colaborador da Escolinha de Arte de Recife (FREIRE, 2017, p. 84). Ana Mae Barbosa (1996, p. 637), em razão dessa ligação, considera que "Paulo Freire esteve ligado à Arte-Educação desde os inícios de sua ação educacional". Ela conta ainda que Paulo Freire manteve contato com a Escolinha de Arte de São Paulo, entre os anos de 1968 e 1971. E mais: conta que lecionaram 
juntos, na Universidade de São Paulo (USP), em 1987, o curso "Arte-Educação e Ação Cultural".

Tampouco podemos deixar de considerar que Paulo Freire foi nomeado professor catedrático interino de História e Filosofia da Educação, em 1952, na Escola de Belas Artes da Universidade de Recife (hoje, Universidade Federal de Pernambuco). Precisamos lembrar também sua atividade no Setor de Educação e Cultura do Serviço Social da Industria (Sesi), a partir de 1947, e sua participação, já no começo dos anos 1960, no Serviço de Extensão Cultural da Universidade de Recife e no Movimento de Cultura Popular (MCP). Inclusive, foi aí, no MCP, que ocorreram as práticas iniciais de alfabetização pelo chamado "Método Paulo Freire" (FREIRE, 2017, p. 104). A propósito do Método, o encontro entre educandos e educadores não acontecia em salas de aula, mas nos assim chamados "círculos de cultura". Arte e cultura estavam constantemente integradas no seu itinerário de educador, está claro. Certamente, trata-se de uma experiência que proporcionou a ele uma determinada singularização na sua concepção de educação.

Portanto, não é sem perspectiva que, nos anos 1970, quando publica no livro Cartas à Guine-Bissau sobre a sua colaboração com o Comissariado da Educação de Guiné-Bissau, Paulo Freire (2011 1, p. 45) dirá, de modo breve, mas seguro: "O educador é um político e um artista". Não se trata de uma mera imagem ou metáfora senão de uma compreensão coerentemente fundada na sua concepção sobre o trabalho do educador. A mesma afirmação será feita, idêntica, também nos anos 1970, em uma entrevista de Paulo Freire (1978, on-line) publicada no periódico espanhol El País: "El educador es un político y un artista". Na década seguinte, Paulo Freire voltará ao tema estimulado pelo educador estadunidense Ira Shor (SHOR; FREIRE), 1996, p. 509), que the pergunta sobre o papel da arte no ensino transformador. Paulo Freire responderá a seu interlocutor chamando atenção para a "natureza estética do ato de conhecer". Diz ainda que a educação é "um ato político e estético", condição que, se reconhecida, tornará o professor "um político melhor e um artista melhor".

Em um vídeo postado na Internet no Canal Leandson S. do You tube, e nomeado Paulo Freire falando de Arte e Educação (2013, on-line), uma colagem de dois 
fragmentos de entrevistas concedidas em espanhol, encontramos Paulo Freire abordando o sentido da estética na educação de forma bastante enfática também. No primeiro segmento do brevíssimo material2, ele diz: "El educador tiene que ser sensible, el educador tiene que ser esteta, tiene que ter gusto. La educación es una obra de arte". No segundo momento da montagem, Paulo Freire diz: "El educador es también artista: él rehace el mundo, él redibuja el mundo, repinta el mundo, recanta el mundo, redanza el mundo". Merecedora de atenção é a corporeidade de Paulo Freire nos dois momentos selecionados. Voz e mãos trabalham para imprimir gravidade e emoção ao que diz. É notável. Há uma importância superior que gostaria de atribuir ao que estava dizendo sobre a propriedade da arte na educação.

Por certo, não poderia deixar de lembrar também um elemento estético que compõe propriamente o chamado Método Paulo Freire que são as chamadas fichas de cultura. Após a pesquisa das palavras geradoras, os encontros nos círculos de cultura começam com a projeção de imagens que representam "situações existenciais" dos educandos. É um procedimento importante do Método porque a projeção de imagens serve, desafiadoramente, para que os educandos se reconheçam como criadores de cultura. Trata-se de uma conscientização a propósito da sua condição social e histórica. Mobilizadora, portanto, entende Paulo Freire (2018a, p. 61). Só assim se sentirão suficientemente implicados com o motivo da própria alfabetização. A alfabetização como um caminho para se estar presente no mundo consciente e criticamente. As referidas imagens das fichas de cultura podem ser produzidas através de técnicas e recursos variados. Inclusive, fotografias (BERINO, 2017, p. 186 e 187)

No livro Educação como prática da liberdade, publicado em 1967, Paulo Freire (1994, p. 117 e 131) chama atenção para o trabalho de dois artistas que fizeram para ele versões das fichas de cultura: Francisco Brennand e Vicente de Abreu (este, especialmente para reprodução no livro, depois que os originais de Francisco Bren-

\footnotetext{
${ }^{2}$ Tratam-se de dois pequenos extratos de gravações mais extensas. Não consegui localizar o conteúdo na íntegra desse material em tempo para a escrita desse artigo. Gostaria de dar crédito a minha orientanda Tatiana Oliveira Melo, que está escrevendo sua monografia de graduação e, na pesquisa que está realizando sobre Paulo Freire e Augusto Boal, encontrou o referido vídeo no YouTube. Orientação que desenvolvo no GRPESQ Estudos Culturais em Educação e Arte da Universidade do Estado do Rio de Janeiro (UERJ).
} 
nand foram tomados com o golpe civil-militar de 1964). "Uma perfeita integração entre educação e arte", Paulo Freire irá se referir assim à pintura inicialmente feita por Francisco Brennand. O fato é que, se percorrermos amplamente a obra de Paulo Freire, é axiomático que a experiência estética sempre esteve presente na sua concepção da educação. No entanto, esse é o "outro lado da moeda", nunca constituiu um motivo demoradamente debatido por ele entre os seus escritos. A questão, portanto, é a seguinte. Se nos fixarmos simplesmente nas muitas passagens em que Paulo Freire enreda a estética em seu pensamento e prática educacional, não nos faltarão referências. Elas realmente são muitas. O problema é que parecem apontar para diferentes caminhos de apreensão sem nos garantir uma direção mais certificada, reveladora de um sentido mais significativo para a sua obra - o que acontece na falta de uma indicação mais eloquente dada pelo próprio Paulo Freire.

O que vou fazer a seguir é propor um caminho para uma compreensão do problema da estética em Paulo Freire atentando para o que vejo como mais correspondente com o seu sistema de pensamento. Em outras palavras, apontar para uma tessitura da questão da estética na sua obra de acordo com aqueles princípios que condizem de modo mais claramente identificável com a sua concepção de educação. Quando Paulo Freire diz que o educador é um político e um artista ou que a educação é uma obra de arte, estes são fragmentos das suas ideias estéticas, na verdade. Precisamos encontrar o núcleo dessas ideias. É o que pretendo apresentar aqui, então. No entanto, uma ressalva precisa ser feita. Trata-se, como já afirmei, de uma pesquisa em curso, com resultados ainda parciais. $\bigcirc$ artigo é parte de um trabalho que demanda mais elaborações que só serão alcançadas um pouco mais adiante.

Paulo Freire começou a pensar a educação diante dos impasses históricos da sociedade brasileira. Isso já aparece em Educação e atualidade brasileira, obra citada anteriormente. Desde o início da sua abordagem sobre a educação brasileira, Paulo Freire é um intelectual incomodado com as carências do país. Via na educação uma oportunidade de desenvolvimento da sociedade brasileira. Ao longo da década de 1960, sua análise vai deixando de ser puramente desenvolvimentista e ganha uma acepção mais dirigida às contradições sociais, tornando-se politica- 
mente emancipatória. Até um Paulo Freire mais marxista poderá ser reconhecido em diferentes passagens posteriores da sua obra. De todo modo, o fato é que, para Paulo Freire, desde o início, a educação está relacionada às possibilidades de mudança. Mudança, transformação e, ainda que de forma bem datada, revolução incluem-se entre os temas políticos claramente identificáveis se percorremos toda a sua obra.

Para Paulo Freire, sem dúvida, a educação é uma prática para uma alternativa social diante das condições opressores socialmente encontradas. Educa-se para a busca de outros destinos, mais associados às liberdades e à autonomia do ser social. Educa-se sempre de forma rebelde, essa é indiscutivelmente uma marca da educação freireana. Em Educação como prática da liberdade, Paulo Freire utilizará alternadamente as expressões "ato de criação", "esforço criador", "ímpeto de criação" e "criação humana" para enfatizar o caráter transformador da existência humana. Em uma concepção lapidar: "Pensávamos numa alfabetização que fosse em si um ato de criação, capaz de desencadear outros atos criadores" (FREIRE, 1994, p. 112). Posso dizer, Paulo Freire via na educação uma ontologia. O homem humaniza-se porque é um criador, e a educação é a condição geradora desse processo.

É através da educação, portanto, que Paulo Freire via a experiência humana radical da criação. A educação como raiz de toda mudança. O que chamamos de mundo, humanamente referenciado, só adquire pleno sentido a partir da educação. É desde a sua prática que acontece a passagem da vida pura e simples em existência no mundo. Com a educação nos situamos melhor diante das coisas e podemos reelaborar a nossa constituição vivente atuando como criadores da nossa própria realidade. Já em Pedagogia do oprimido, escrito em 1968, Paulo Freire (2005, p. 83) introduz o conceito de "ser mais" como uma condição permanente do humano. A "pedagogia do oprimido" é a pedagogia que se opõe à "pedagogia bancária", que Paulo Freire criticava, de transferência e não de criação de conhecimento com o educando. A pedagogia bancária é retrógada, não expansiva da existência. Sem poder se comprometer autenticamente com um caráter emancipatório para a educação, ela é caracteristicamente imobilista e castradora da 
transformação como liberdade.

Com o conceito de "ser mais" Paulo Freire aprofunda sua antropologia da educação afirmando o caráter inconcluso da existência humana, permanentemente criador, que ele vai chamar também de "devenir da realidade" (FREIRE, 20015, p. 84). Educa-se para devir, consciente do inacabamento e insubmisso ao presente, desperto das condições existentes e desejadamente transformáveis. Essa é a pedagogia do oprimido, que não aceita o fatalismo da opressão e pretende a emancipação como um ato criador. O conceito de "ser mais" atravessará toda a obra posterior de Paulo Freire, marcando sua concepção da educação com uma visão de mundo que assinala a impermanência dos estados da existência e a busca sucessiva de novas realidades. Importante dizer que não se trata de uma visão de mundo metafísica, mas socialmente condicionada. Paulo Freire não nos fala da transformação como mudanças sucessivas das formas de existência sem interesses sociais e historicamente verificáveis. Para Paulo Freire, a humanização do oprimido é libertar-se. A educação é política, ele nunca deixará de dizer.

O que gostaria de propor sobre o problema da estética na obra de Paulo Freire, portanto, é que a abordagem mais consistente para discutir essa importância para Paulo Freire, é entender que ele via educação como criação. É a partir daí, dos conceitos que criou para fundamentar essa sua compreensão, que é possível reconhecer o sentido que atribuía à estética na sua relação com a educação, que ele afirma ao longo de toda a sua obra. O princípio de que somos incompletos, inacabados ou inconclusos, expressões que utilizará recorrentemente, e de que a educação se realiza através dessas "janelas" existenciais, como criação, é o núcleo do pensamento estético de Paulo Freire.

Em 1996, um ano antes de nos deixar, dando um seminário na Argentina, Paulo Freire (2018b, p. 26) utiliza ainda uma outra expressão: "somos interminados". A adoção dessa palavra já constitui a oportunidade de um refinamento analítico na pesquisa sobre a estética na sua concepção da educação. Entendo que a ideia de que somos intermináveis cria um certo atrito com as categorias incompletos, inacabados ou inconclusos, que me parecem mais articuláveis a uma concepção de falta constitutiva. "Interminável" sugere um movimento para fora, livre de qualquer 
sentido de insuficiência e de destituição. É uma possibilidade que pretendo explorar na sequência da minha pesquisa, apresentada aqui ainda em estado de desenvolvimento, comojá assinalei.

Passo agora às palavras de Paulo Freire que estão na epígrafe deste artigo. Trata-se de uma passagem do texto Ação cultural para a libertação, publicado em 1969, no livro Ação cultural para a liberdade e outros escritos. Paulo Freire (1987, p. 57) prossegue o fragmento que citei assim: "Tudo isto constitui sua linguagem, como 'linguagem total', e são valores que compõem aquela muralha e que, mesmo tocados pela ideologia dominante, não se entregam totalmente a ela". Por que as palavras de Paulo Freire parecem conter aí uma imediata atualidade, mesmo após meio século? O que reproduzi na epígrafe constitui uma percepção estética das classes populares que agora, incontestavelmente, seria compreendida como um reconhecimento cultural. São palavras de Paulo Freire que poderiam ser dirigidas ao funk (sua música), a corporeidade e a linguagem dos funkeiros. São palavras apropriadas para o que significam como cultura das populações "periferizadas", sua resistência e luta: "mesmo tocados pela ideologia dominante, não se entregam totalmente a ela".

A experiência estética de muitos jovens das favelas está, já nas últimas décadas, entre as mais expressivas da cultura popular, pelo que representam como desafio à ideologia do preconceito na sociedade brasileira. São criações que se impõem e buscam consolidar a presença das classes populares na vida das cidades, território da legitimidade social, contra o poder. A estética, muitas vezes, é a visibilidade dos pobres. "O uso do corpo, seus gestos, sua maneira de andar, de vestir" constituem "presentificações" dos "favelados", população a que se refere Paulo Freire no texto. Indivíduos que criam uma "linguagem total" para que possam (re)existir. Recuperar o pensamento estético de Paulo Freire é um movimento de atualização do seu legado para o desafio da educação popular no século XXI. Existe também, importante notar, um capitalismo cada vez mais fascinante, em razão dos seus processos de aprisionamento através da estética. Uma "estetização do mundo", como disseram Gilles Lipovetsky e Jean Serroy (2015). Muito do que existe de criação na cultura popular na contemporaneidade é porque, como disse Paulo Freire há cinquenta 
anos, "não se entregam totalmente a ela", à estetização do mundo como uma obra do capitalismo, produzindo outras estéticas, diante das compressões que encontram como população marginalizada.

Identifico ainda outra categoria utilizada por Paulo Freire que gostaria de associar como pertinente ao que concebia como criação, principalmente em razão do seu significado mais atual: Sonho. Inicialmente pode parecer sem propósito misturar a experiência imaginativa e desejante do sonho com uma chamada à criação como uma ação referida ao fato social da educação. No entanto, como assinalou Ana Lúcia Souza de Freitas (2008, p. 390), "o sonho, na visão de Paulo Freire, tem forte conotação política e está associado à visão de história como possibilidade". Ela observa também que trata-se de um tema que ficou mais explícito na obra de Paulo Freire a partir da década de 1980 (FREITAS, 2008, p. 391). Seguindo Ana Lúcia Souza de Freitas nesta observação, vejo que a recorrência mais tardia de Paulo Freire a uma "política do sonho" está estreitamente ligada ao contexto devastador no neoliberalismo diante das utopias, a partir do período identificado.

Em um depoimento registrado em sua casa, no seu último ano de vida, em 1997, posteriormente publicado como um texto na Austrália, diz Paulo Freire (2001, P. 35 e 36): "Para mim, é impossível existir sem sonhos. Como é que podemos aceitar esses discursos neoliberais que vêm sendo apregoados como verdadeiros e manter vivos os nossos sonhos?" O discurso neoliberal é visceralmente contemporizado e paralisante. Seu sentido é antagônico à ideia de mudança e transformação, mesmo no plano reformista. A respeito das utopias e dos sonhos revolucionários que atravessaram de modo agudo a década 1960 até os anos de 1970, a narrativa neoliberal imobiliza o pensamento social, inclusive educacional, rejeitando frontalmente qualquer pedagogia que pretenda contrapor e emancipar, como propunha Paulo Freire.

Contra toda política de (re)existência, geradora de outras condições sociais, mais soberanas e autônomas, o pensamento neoliberal é depressivo com a sua invocação de uma realidade fixada que se impõe acima de qualquer ideação de liberdade. A repetição do tema do sonho em Paulo Freire, a partir dos riscos de uma hegemonia neoliberal, é parte da sua luta contra a concepção de desaparecimen- 
to da história como processo vivo, sucessivamente articulado pelas pessoas, notadamente as "de baixo". "Impossível viver sem sonhos" - o que equivale dizer, para a minha discussão aqui: Impossível viver sem ser virtualmente um criador. "Penso que seja de nosso dever lutar contra essas formas fatalistas e mecânicas de compreender a história", diz Paulo Freire (FREIRE, 2001, p. 36), apontando para a amalgama que existe entre história e sonho, entre vida humana e criação. O lado da estética em Paulo Freire é o lado do encetamento sem cessar que é a existência humana.

Em Pedagogia da esperança, livro de 1992, há uma passagem do texto dedicada às críticas, segundo Paulo Freire (2011, p. 123), "que se diziam marxistas", na década de 1970, feitas a ele. Uma negativa seria a suposta ausência das "classes sociais" na obra Pedagogia do oprimido. Depois de recusar tal crítica, Paulo Freire (2001, p. 125) apresenta sua compreensão sobre como operar com o conceito de luta de classes: "Não é o motor da história, mas certamente é um deles". Consideração que precede e me parece importante para avaliar sua abordagem, a seguir, a respeito do "sonho". Reagindo ao discurso pragmático e conformado que, então, buscava se consolidar como dominante, diz Paulo Freire (2001, p. 126): "Sonhar não é apenas um ato político necessário, mas também uma conotação da forma histórico-social de estar sendo de mulheres e homens". Mais adiante, prossegue; "Virando seres da inserção no mundo e não pura adaptação ao mundo terminaram por ter no sonho também um motor da história".

Portanto, recusando uma visão mais determinista de luta de classes, Paulo Freire vê no sonhar um protagonismo correlato também ao "motor da história". Como já anotei, a categoria sonho aqui não adquire o sentido abstrato do devaneio. Paulo Freire fala do sonho como uma tessitura política, um elemento da própria atividade criadora, transformadora da realidade social. No livro Cartas pedagógicas, que estava escrevendo, mas permaneceu incompleto quando nos deixou, publicado postumamente como Pedagogia da indignação, afirma Paulo Freire (2000a, p. 54): Os sonhos são projetos pelos quais se luta." Apesar do refluxo das ideias de mudança social provocado pelo avanço do neoliberalismo, Paulo Freire seguia perseguindo a ideia de que a existência humana implica a possibilidade de alternativas à vida e a capacidade de sonhar é uma propriedade da nossa vitalidade. 
Em outro texto, publicado de modo complementar em Pedagogia da indignação, Paulo Freire lembra uma conhecida passagem de Marx (2013, p. 255 e 256) em $O$ capital para dimensionar o sentido antropológico que atribuía ao sonho. Trata-se da comparação que Marx faz entre as operações da aranha e da abelha com o trabalho do tecelão e do arquiteto, cujo resultado, ele diz, "já estava presente na representação do trabalhador no início do processo, portanto, um trabalho que já existia idealmente". Paulo Freire (2000b, p. 132 e 133) recorda Marx para afirmar também, a propósito da "atividade criativa" humana: "temos também na cabeça, mais ou menos, o desenho do mundo em que gostaríamos de viver. Isto é a utopia e o sonho que nos instiga a lutar." A ênfase com que Paulo Freire referiu-se ao sonho em período da história em que os projetos de transformação social já apareciam mais retraídos comparativamente com as décadas anteriores visava revalidar sua concepção criadora da educação - essencialmente causadora de outros sentidos para a existência humana.

Paulo Freire, em momentos diferentes da sua obra, usou diretamente a palavra estética e ainda outras palavras e ideias com um sentido correspondente para caracterizar a sua concepção de educação. Além da indicação explícita de que é decididamente uma categoria do seu pensamento pedagógico, encontramos na sua obra uma extensa análise dos processos educativos em que a questão da "criação" é o que nos dará o sentido mais significativo sobre o que Paulo Freire atribuía à estética. Para o propósito deste artigo, consideramos uma representação significativa da sua obra, de seus primeiros escritos divulgados até as suas últimas publicações, identificando as recorrências com as quais abordou a questão da estéti$\mathrm{ca} /$ criação e os seus sentidos para a educação. O procedimento foi considerar o modo como tal problemática aparece na sua concepção pedagógica mais ampla e visão do próprio "homem", tendo em vista que para Paulo Freire, a educação crítica aclara sobre a nossa condição no mundo, sempre histórica e inacabada/interminada - o "ser mais" que aparece na sua formulação antropológica e filosófica da educação.

Paulo Freire permanece atual e, por isso, tem sido tão perseguido por inúmeros detratores. O próprio presidente Bolsonaro e seu ministro da educação Weintra- 
ub, já se manifestaram inúmeras vezes de forma odiosa contra ele. Há também o movimento Escola Sem Partido, entre outras articulações, combatendo o legado de Paulo Freire. Não vamos esquecer que já no ambiente político que antecedeu ao golpe civil-militar de 1964 e no curso dos acontecimentos ele foi estigmatizado e logo perseguido. No último encontro da campanha de alfabetização na cidade Angicos, no Rio Grande do Norte, em 1963, sua experiência pedagógica mais reportada, entre os convidados estava o comandante do IV Exército, o general Humberto de Alencar Castello Branco, que teria confidenciado a um interlocutor sua preocupação com o trabalho desenvolvido por Paulo Freire, pois serviria "para engordar cascavéis nesses sertões" (HADDAD, 2019, p. 72). Castello Branco virou o primeiro presidente militar da ditadura e Paulo Freire precisou ir para o exílio.

Em 1980, Paulo Freire retorna definitivamente ao Brasil. Somos nós, no entanto, que sucessivamente retornamos à Paulo Freire, pesquisando sua obra, descobrindo novas perspectivas analíticas para abordá-la e criando novos objetos de atenção. Paulo Freire foi um personagem do século XX, mas a sua existência nos alcança através de uma obra que ainda está sendo consolidada com a publicação de originais. Uma leitura viva de Paulo Freire é aquela que é capaz de procurar no seu pensamento e na sua prática algo que nos interessa agora, na contemporaneidade. Quem sabe uma fenda na sua obra já tantas vezes apresentada e explicada pela qual poderíamos adentrar e alcançar o que precisamos dele para lidar com os "temas geradores" da nossa época. Acredito que o tema da estética é uma dessas oportunidades. 


\section{Referências Bibliográficas}

BARBOSA, Ana Mae. Paulo Freire e a arte-educação. In: GADOTTI, Moacir (org). Paulo Freire: uma biobibliografia. São Paulo: Cortez/Instituto Paulo Freire; Brasília: UNESCO, 1996. p. 637-639.

BERINO, Aristóteles. Paulo Freire esteta: arte, fotografia e cinema. E-Mosaicos, Rio de Janeiro, v. 6, n. 13, p. 182-192, 2017.

FREIRE, Ana Maria Araújo. Paulo Freire: uma história de vida. 2. ed. rev. atualizada. Rio de Janeiro/São Paulo: Paz e Terra, 2017.

FREIRE, Paulo. Ação cultural para a libertação. In: Ação cultural para a liberdade e outros escritos. 8. ed. Rio de Janeiro: Paze Terra, 1987. p. 42-85.

FREIRE, Paulo. A confrontação não é histórica e sim política. Entrevista In: FREIRE, Paulo. Pedagogia do compromisso: América Latina e educação popular. Rio de Janeiro/São Paulo: Paze Terra, 2018a. p. 55-63.

FREIRE, Paulo. Cartas à Guiné-Bissau: registros de uma experiência em processo. 5. ed. São Paulo: Paze Terra, 2011.

FREIRE, Paulo. Denúncia, anúncio, profecia, utopia e sonho. In: Pedagogia da indignação: cartas pedagógicas e outros escritos. São Paulo: Ed. da Unesp, 2000a. p. 117-134.

FREIRE, Paulo. Educação como prática da liberdade. 22. reimp. Rio de Janeiro, Paze Terra, 1994.

FREIRE, Paulo. Educação e atualidade brasileira. 2. ed. São Paulo: Cortez/IFP Instituto Paulo Freire, 2002.

FREIRE, Paulo. La educación es siempre un quehacer político. Entrevista concedida a Karmentxu Marín. El País, Madri, 20 maio 1978. Disponível em <https://elpais.com/diario/1978/05/20/sociedad/264463223_850215.html> Acesso em: 5 set. 2017.

FREIRE, Paulo. Impossível existir sem sonhos. In: Pedagogia dos sonhos possíveis. São Paulo: Ed. UNESP, 2001. p. 35-40.

FREIRE, Paulo. Pedagogia da autonomia: saberes necessários à prática educativa. 51. ed. Rio de Janeiro: Paz e Terra, 2011. 
FREIRE, Paulo. Pedagogia da esperança: um reencontro com a pedagogia do oprimido. 17. ed. São Paulo: Paze Terra, 2015.

FREIRE, Paulo. Pedagogia do oprimido. 44. ed. Rio de Janeiro: Paz e Terra, 2005.

FREIRE, Paulo. Prática da pedagogia crítica. In: FREIRE, Paulo. Pedagogia do compromisso: América Latina e educação popular. Rio de Janeiro/São Paulo: Paz e Terra, 2018b. p. 25-34.

FREIRE, Paulo. Segunda carta - do direito e do dever de mudar o mundo. In: Pedagogia da indignação: cartas pedagógicas e outros escritos. São Paulo: Ed. da Unesp, 2000b. p. 53-63.

FREITAS, Ana Lúcia Souza de. Sonho Possível. In: STRECK, Danilo R.; REDIN; Euclides; ZITKOSKI, Jaime José. Dicionário Paulo Freire. Belo Horizonte: Autêntica, 2008. p. 390392.

HADDAD, Sérgio. O educador: um perfil de Paulo Freire. São Paulo: Todavia, 2019. LIPOVETSKY, Gilles; SERROY, Jean. A estetização do mundo: viver na era do capitalismo artista. São Paulo: Companhia das Letras, 2015.

MARX, Karl. O capital: crítica da economia política. Livro I-O processo de produção do capital. São Paulo: Boitempo, 2013.

PAULO FREIRE falando de Arte e Educação. 2013?. Vídeo (48s). Disponível em: https://www.youtube.com/watch? $v=u 5 F d t 4 T D T R Y \& f b c l i d=I w A R O F o o W i z R v C v R 9 R e s i$ V_Lx_hhnlxDMLmBikNRVJu2g9nLipRVo_7yMQ9Wo. Acesso em: 26 ago. 2019.

SHOR, Ira; FREIRE, Paulo. O professor como artista. In: GADOTTI, Moacir (org). Paulo Freire: uma biobibliografia. São Paulo: Cortez/Instituto Paulo Freire; Brasília: UNESCO, 1996. p. 509. 